\title{
LA FOTOGRAFÍA EN LA INVESTIGACIÓN EDUCATIVA BASADA EN LAS ARTES
}

\section{Dr. José María Mesías-Lema}

Universidad da Coruña (D) https://orcid.org/0000-0001-8278-7115

\section{Dr. Ricard Ramon}

Universitat de València (D) https://orcid.org/0000-0003-1009-2589

\section{Resumen}

Este artículo analiza el uso de la fotografía como artefacto y documentación pedagógica de la investigación educativa basada en las artes. Su puesta en práctica se materializa a través del proyecto colaborativo "Maneras de hacer mundos", entre dos universidades españolas. Este ahonda en los discursos docentes, sus metodologías y su pensamiento a través de acciones performativas mediante el uso de la fotografía. Dichas acciones constituyen una manera de subvertir el aula y reflexionar sobre ella, sobre todo, al centrarnos en la formación inicial del profesorado en artes visuales. Los resultados de las acciones permiten visualizar los espacios de reflexión y análisis que los participantes desarrollan con su propio cuerpo, adquirir una nueva forma de pensar y ofrecer un instrumento de acción artística para actuar educativamente en sus aulas en el futuro.

\section{Palabras clave}

acciones performativas; investigación educativa basada en las artes; fotografía; educación artística; formación docente; cultura visual.

\begin{abstract}
This article discusses the use of photography as a pedagogical artefact and documentation tool for Arts-based Educational Research. Its implementation is accomplished through the collaborative project "Ways to make worlds", developed by two Spanish universities. This project delves into the educational discourses, methodologies and thinking through performative actions using photography. These actions constitute a means of subverting the classroom and reflecting on it, above all, by focusing on the initial training of teachers in the visual arts. The results of the actions allow us to visualize the spaces of reflection and analysis that the participants develop with their own bodies, acquiring a new way of thinking and offering an instrument of artistic action to engage educationally in their future classrooms.
\end{abstract}

\section{Key words}

performative actions; Arts-based Educational Research; photography; art education; teacher training; visual culture. 


\section{INTRODUCCIÓN}

El impulso investigador de carácter creativo durante los últimos veinte años, ha sido posible por la influencia de discursos críticos, activistas, feministas, participativos, democráticos o etnográficos, propios de campos tan plurales como el artístico (Janesick, 2003), y configuran una manera más congruente de explorar la complejidad social del mundo contemporáneo. Dentro del paradigma posmoderno y de modernidad líquida (Bauman, 2003), el debate acerca de la necesidad de nuevos modos de abordar el conocimiento, también en la investigación artística (Arts-Based Research), está en auge, principalmente en el campo de la educación y de la arteterapia.

Investigar con una metodología artística es hacerlo desde la tensión establecida entre la visión estética, divergente e inconformista del arte y lo que esta aporta a los procesos educativos. Este enfoque exige afrontar la investigación desde una mirada poliédrica, no reduccionista y plenamente integradora de los modos de crear y producir arte en el mundo de la educación. Por esta razón profundizaremos en las intersecciones que posibilitan la emergencia de la Investigación Educativa basada en las Artes. Inicialmente, esta bebe de las fuentes del paradigma cualitativo, influenciado por la investigación-acción participativa/Participatory Action Research (James, Milenkiewick y Bucknam, 2008) y del giro narrativo en la investigación educativa (Denzin, 1989; Bolivar, Domingo y Fernández, 2001; Goodley, 2004) y artística.

Dado el carácter eminentemente social de la Investigación Educativa basada en las Artes, se han publicado varios handbooks que muestran el impacto de la Artsbased Educational Research en los procesos educativos y artísticos contemporáneos (Mulvihill \& Swaminathan, 2020): Handbook of Arts-Based Research (Leavy, 2018); The Routledge International handbook of Arts and Education (Fleming, Bresler \& O'Toole, 2015); The Oxford handbook of Qualitative Research (Leavy, 2014); The sage handbook of qualitative research (Denzin \& Lincoln, 2011); The Routledge International Handbook of creative learning (Sefton-Green, Thomson, Jones \& Bresler, 2011); Qualitative Inquiry: Thematic, Narrative and Arts-based Approaches (Butler-Kisber, 2010); Handbook of Public Pedagogy (Sandlin, Schultz \& Burdick, 2010); Handbook of Emergent Methods (Leavy, 2008); Handbook of Research and Policy in Art Education (Eisner \& Day, 2004).

\section{LA INVESTIGACIÓN BASADA EN LAS ARTES / Arts-Based Research}

En la investigación en educación artística, el debate se sitúa en torno al desarrollo de un nuevo enfoque metodológico basado en procesos artísticos (Agra, 2005; Sullivan, 2005; Bresler, 2007, Cahnmann-Taylor \& Siegesmund 2008; Hernández, 2008; Irwin \& Springgay, 2008; Butler-Kisber, 2010; Marín, 2011, Barone \& Eisner, 2012; Mesías-Lema, 2012; Leavy, 2015). La investigación basada en las artes utiliza la metodología propia de las disciplinas artísticas: danza, teatro, performance, pintura, fotografía, escultura, cerámica... y no solo se vale de lo textual, sino que, coherentemente, utiliza los lenguajes estéticos, productivos y discursivos de la materia artística sobre la que se investiga. Shaun McNiff (2004, pp. 49-50) afirma que la Arts-based Research y la investigación científica tienen en común el compromiso con la innovación y la imaginación creativa. Es el "cientifismo" el que trata de marcar distancias con los métodos artísticos.

La originalidad de la Arts-Based Research reside en la integración de métodos introspectivos, autobiográficos y personales sin renunciar al análisis profundo del discurso. Las investigaciones en el terreno artístico huyen de laboratorios asépticos que controlan todas las variables cuantificables porque, entre otras cosas, el arte está inmerso en la vida y la vida es de todo menos esterilizada, cuantificada y predecible. Además, si nos 
referimos a la introspección personal como un modo de investigación basada en la identidad, se estimula la narración de historias de vida, experimentadas en primera persona por el artista-investigador que, sin duda, en ciencias sociales y educación, nos ayudan a avanzar en la teoría desde la práctica y no al revés.

Posicionarse desde el terreno de la investigación artística, supone una tarea sumamente estimulante y especialmente discreta. Estimulante por la pasión y entrega hacia un campo de conocimiento caracterizado, principalmente, por la innovación, originalidad y utilidad de las aportaciones visuales y textuales. Discreta, en el sentido de responsabilidad profesional. Las críticas que atañen a esta modalidad de indagación coinciden en entender la narrativa personal como subjetiva. Esta malinterpretada subjetividad produce incertidumbre científica y por ello, como investigadores, debemos afrontar nuestro trabajo bajo la ética del riesgo, asumiendo con el mayor compromiso profesional la complejidad de este tipo de indagación artística.

\section{LA INVESTIGACIÓN EDUCATIVA BASADA EN LAS ARTES}

Barone y Eisner (2006) afirman que la Investigación Educativa basada en las Artes (ABER) se debe a dos criterios indisociables. En primer lugar, la ABER pretende intensificar las acciones humanas asociadas a la actividad artística (artes visuales, plásticas, escénicas, musicales, etc.), pero con carácter educativo y, consecuentemente, formativo. En segundo lugar, la $A B E R$ se caracteriza por la presencia de cualidades estéticas o elementos de diseño que acompañan tanto al proceso de investigación, como al objeto artístico elaborado durante la investigación. Estas cualidades estéticas serán diferentes en función de la parcela artística en dónde se sitúe el investigador.

Podemos decir que la ABER es una forma de investigar en contextos educativos a través de procedimientos, técnicas, documentos, metodologías y estrategias artísticas. El propósito de la ABER es abrir nuevas perspectivas de acción artística mucho más situadas en los fenómenos educativos sobre los que investigan. El cambio en el modo de investigar y presentar los resultados tiene dimensiones creativas, estéticas y artísticas. La ABER genera preguntas que orientan el conocimiento pragmático desde el aprendizaje de los procesos artísticos en educación. No se puede entender una ABER desde un punto de vista puramente teórico, desvinculada de la realidad educativa. Ambos campos, el educativo y el artístico, se caracterizan por los contextos orgánicos y de acción, por tanto, una investigación teórica desvinculada de la práctica no tiene cabida en este tipo de metodología.

Esta visión artística de la investigación educativa requiere la utilización de lenguajes más acordes con las manifestaciones contemporáneas: instalación, live-cinema, performances, happenings, net-art, body-art, video-art, land-art, etc. El investigador observa en profundidad el contexto educativo, no para analizarlo somera y previsiblemente, sino para propiciar con metodologías artísticas una actitud creativa que permita comprender lo que sucede en los contextos educativos.

La ABER posee una serie de ventajas (citadas en Agra, 2005, p.138; Marín 2005, p.253; Hernández, 2008 y Barone \& Eisner 2012, p. 41): Reflexividad, a través de la introspección de nuestra identidad como investigadores; Empatía, porque llegamos a comprender de una manera más profunda los contextos situacionales y las personas que están inmersos en ellos; Autenticidad y sensación de realidad; Coherencia con la complejidad educativa y artística (la ABER implica un proceso de aprendizaje complejo y el material artístico producido muestra, de forma evocativa, la complejidad del contexto situacional investigado mejor que otras formas de discurso académico); Pluralidad y profundidad de las preguntas; Enfoque holístico que amplía la capacidad y la mirada del investigador; Capacidad de asombro, haciendo que lo ordinario se vuelva extraordinario, en la 
medida en que provoca, innova y quiebra resistencias, llevándonos a considerar nuevas maneras de ver o hacer las cosas; Comunitario, haciendo lo personal social y lo privado público.

Del mismo modo, también existen una serie de inconvenientes a la hora de desarrollar este tipo de investigación. En el ámbito académico sigue habiendo resistencias que tienen su origen en la utilización de lenguajes híbridos con presencia de elementos no textuales y que no son contemplados por un sistema tradicional con normas rígidas de publicación (tesis doctorales, revistas de investigación o handbooks). Lo nuevo siempre plantea interrogantes, inseguridades y dudas que colisionan con el supuesto rigor científico. Con esto no se quiere defender que en la ABER todo valga. Somos conscientes del peligro de que, al amparo de esta metodología flexible, se presenten investigaciones poco profundas o de baja calidad. Pero esto no debería ser un impedimento para un cambio, tanto en la manera de pensar en los contextos académicos como para ampliar el propio concepto de investigación a otras formas de presentación de los trabajos científicos. Conseguir el pleno reconocimiento de este tipo de investigaciones es un reto que implica a toda la comunidad de investigadores en Educación Artística.

En el ámbito artístico son muchos los artistas que manifiestan su reticencia sobre que una obra o proceso artístico pueda adaptarse mediante recetas o fórmulas a un traje hecho a medida de la investigación científica. Desde su punto de vista, la estética ya posee un lenguaje, discurso y corpus propio y, por lo tanto, no necesita justificarse constantemente para el beneplácito en otros ámbitos de conocimiento.

En el ámbito personal la investigación se asocia a una supuesta objetividad que entra en colisión con la filosofía de un investigador implicado en la ABER. La experiencia personal del investigador es necesaria porque este se ubica dentro de un contexto situacional para observar y participar en él. No se encuentra al margen, sino que, como sujeto participante, se filtra por las fisuras del proceso investigador. Esto puede plantear problemas a la hora de dar "validez" científica a la ABER. El investigador, al formar parte de una comunidad como un sujeto más, ha de ser especialmente cuidadoso con cómo su vivencia personal afecta al proceso. En ocasiones la visión de un acontecimiento puede estar condicionada por contaminaciones del inconsciente.

\section{PHOTOGRAPHY-EDUCATIONAL BASED RESEARCH (PEBR)}

Este tipo de ABER es un método visual que trabaja con fotografía en contextos educativos desde una triple dimensión (descriptiva, interpretativa y artística) y responde, en primer lugar, al potencial de la fotografía como un tipo específico de imagen con carácter propio, definitorio y exclusivo, cuya práctica, reflexión y producción para la investigación sobre las acciones educativas sea fotográfica. En segundo lugar, concibe la fotografía desde una doble vertiente: por un lado, como práctica artística contemporánea dentro del contexto educativo, formativo e investigador; y, por otra parte, como reflexión del proceso de aprendizaje artístico del alumnado. Esto implica pensar en la fotografía desde una mirada introspectiva que cuestiona cómo observamos, producimos e interpretamos fotografías, pero que también repara en el sujeto, al preguntarnos cómo somos mirados, cómo miramos a los demás e, incluso, reconociendo la mirada del otro en los procesos de enseñanza y aprendizaje (Prosser, 1998). Por último, la fotografía se establece como método investigador porque nos permite aproximarnos de modo interpretativo a las narrativas fotográficas del alumnado, infiriendo nuevas perspectivas científicas y tecnológicas encaminadas hacia un conocimiento más exhaustivo sobre la relación entre la investigación y la práctica en la educación de las artes visuales. 


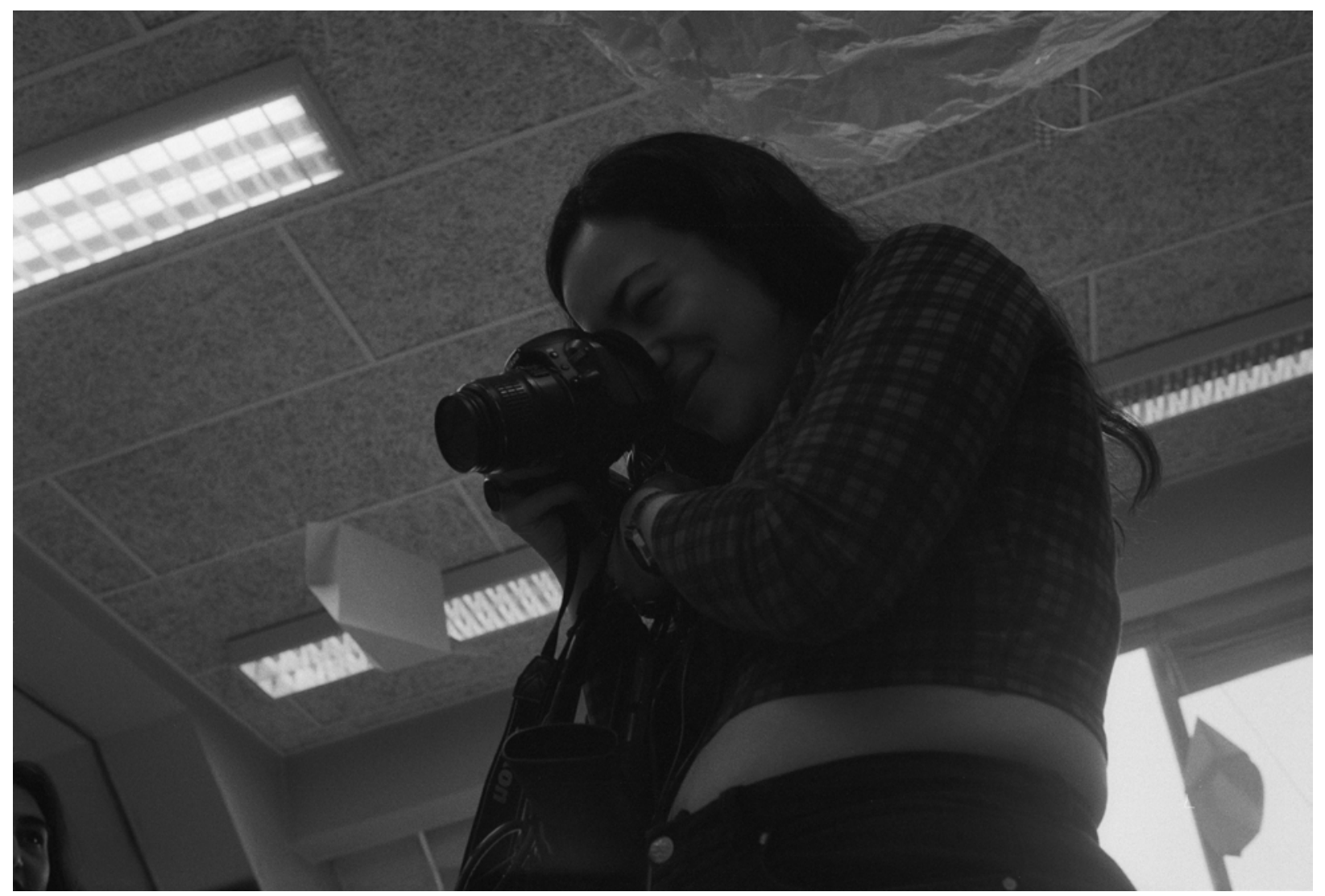

Imagen 1. Alumna trabajando en el proyecto con su cámara. Fuente: autores.

Estamos de acuerdo con Ricardo Marín (2019) cuando propone entender la imagen como argumentación científica en la Investigación Educativa basada en la Fotografía, al mismo nivel epistemológico que lo textual. Esta debe ser articulada como un discurso fotográfico, de manera muy similar a la forma de explicar y citar textos o fragmentos de texto en trabajos de carácter investigador. Independientemente de la manera en que se presente lo visual en las publicaciones académicas, la fotografía ha demostrado ser un instrumento absolutamente trascendente y revolucionario en la investigación educativa. Su utilización se ve reflejada de dos modos, como documentación visual de los actos pedagógicos y como creación artística que genera las propias acciones pedagógicas en el aula de educación artística.

\section{LA FOTOGRAFÍA COMO DOCUMENTACIÓN VISUAL DE LOS ACTOS PEDAGÓGICOS}

La fotografía es esencial como instrumento de análisis, reflexión y autoevaluación del propio trabajo docente, y permite una mayor integración del profesor con el trabajo de sus estudiantes. Además, permite valorar todos los procesos del aula y disponer de una memoria visual de las prácticas educativas desarrolladas, con la finalidad de mejorar su práctica, renovarla y adaptar su metodología. La documentación visual de los actos pedagógicos constituye una verdadera ABER cuando es capaz, no sólo de mostrar el proceso, sino de constituir evidencias científicas a nivel visual, capaces de abrir nuevas líneas de acción docente para la calidad de la educación artística en el aula. Por esta razón, la utilización de la fotografía a la que nos referimos, difiere de la mera función documental que encontramos en investigaciones en las que el docente no participa y deja total libertad al alumnado, sin que haya una formación seria detrás de las acciones artísticas realizadas en el contexto educativo.

Nuestra propuesta del uso científico de la fotografía entiende que esta no funciona como un simple registro o un mero testigo de los acontecimientos, sino que se integra en la 
propia práctica del docente, como investigador y desde una posición artística. Cuando el docente habita el aula con su cámara, pasa a ser un actor más de esta experiencia, como lo es de forma permanente en las prácticas pedagógicas cotidianas. Esta metodología científica se completa con la visualización de las fotografías y el conocimiento compartido entre docentes y estudiantes, como resultado visual de las imágenes entendidas como artefactos. Se cierra así un círculo permanente de aprendizaje colaborativo en el que intervienen todos los participantes de la investigación educativa basada en las artes.

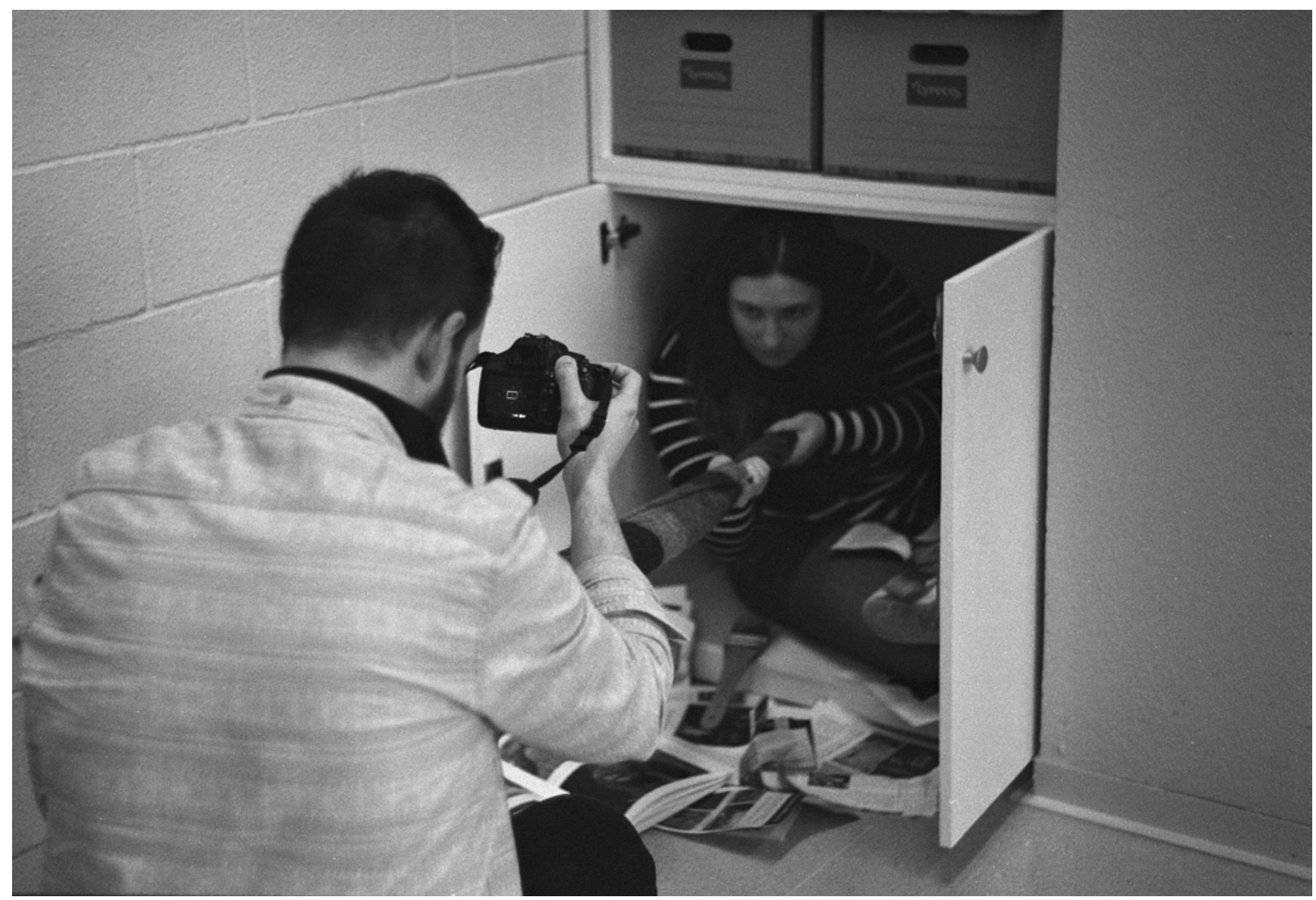

Imagen 2. Un par de alumnos experimentando con la fotografía en el aula a partir del proyecto ABER planteado. Fuente: autores.

El relato visual narrativo de las prácticas docentes y de los procesos de aprendizaje es un agente activo y fundamental, que participa del proceso y no se limita a testimoniarlo como mero observador. Desde el propio momento en el que se establece la acción de tomar fotografías del trabajo y de la práctica educativa de los alumnos, el docente se integra de una forma mucho más íntima y se aproxima a la comprensión profunda del proceso de ese trabajo con el máximo interés. El objetivo debe ser captar con imágenes la esencia de las prácticas y el proceso de pensamiento de sus propios alumnos. De esta manera, el alumnado percibe el interés y la implicación del docente en el proceso de enseñanza-aprendizaje y su integración en un trabajo que percibe como una acción colectiva.

Se trata, también, de una indagación visual y una creación artística y estética, en un sentido esencial y simbólico-significativo, del proceso de aprendizaje. La fotografía, dentro de este modelo particular de documentación, genera que el alumnado pueda ver y reflexionar sobre su propio trabajo, junto al docente, asumiendo el rol de investigador activo de su aprendizaje, amplificando así de manera notable las posibilidades pedagógicas de cualquier práctica. 


\section{LA FORMACIÓN DE PROFESORADO A TRAVÉS DE LA FOTOGRAFÍA ARTÍSTICA CONTEMPORÁNEA}

Utilizar la fotografía en la formación del profesorado constituye una metodología de trabajo fundamental y prioritaria, y no se debe circunscribir únicamente al ámbito de los profesionales de la educación artística. Vivimos en una sociedad y un tiempo en el que el uso de las imágenes constituye una de las vías de comunicación, información, aprendizaje y creación de conocimiento principales. Un hecho que se constata repetidamente, pero no por ello debemos dejar de insistir, es que el uso, la utilización y la presencia de las imágenes en el entorno social no se ve reflejado en las aulas.

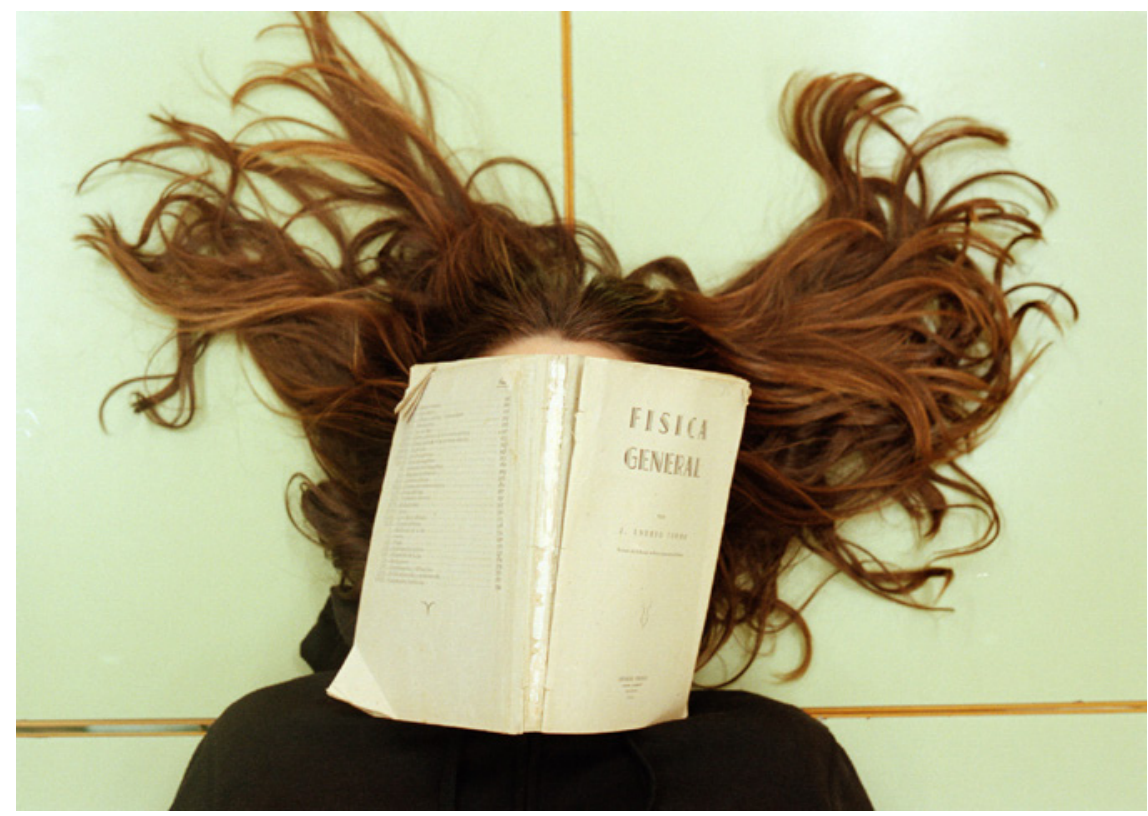

Imagen 3. Maneras de Hacer Mundos. Fotografía analógica. València, 2017. Fuente: autores.

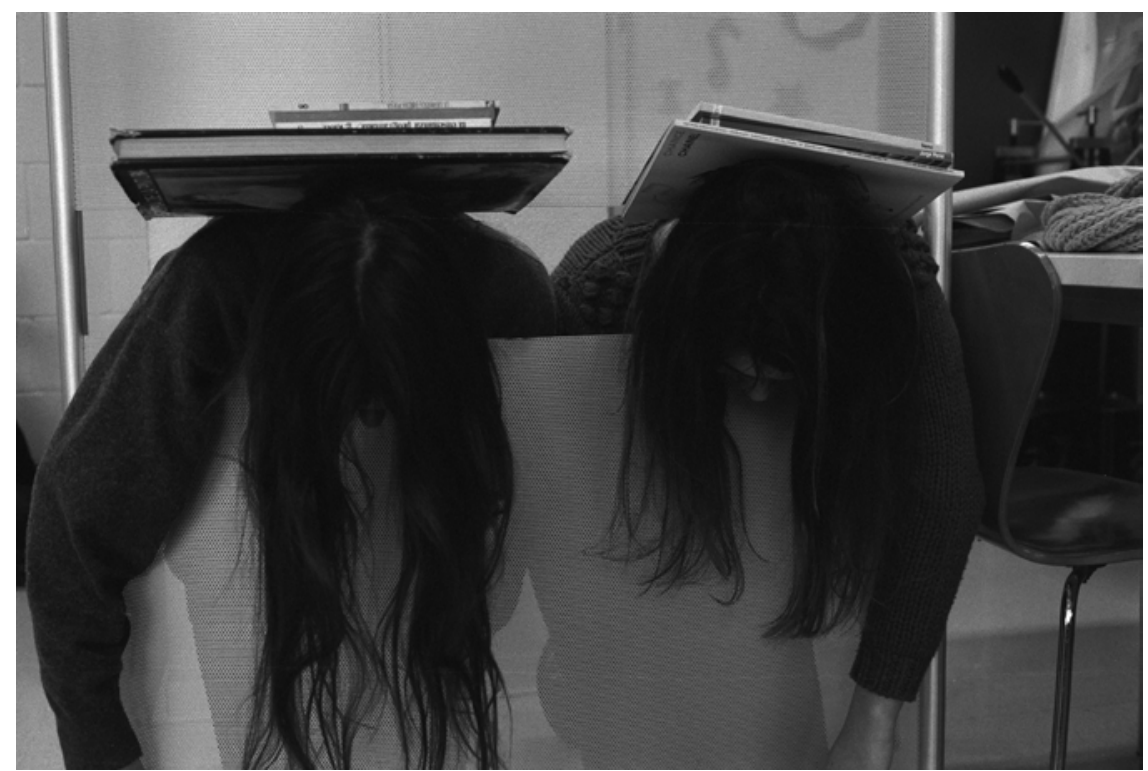

Imagen 4. Alumnas experimentando para el proyecto "Maneras de Hacer Mundos". Fuente: autores. 


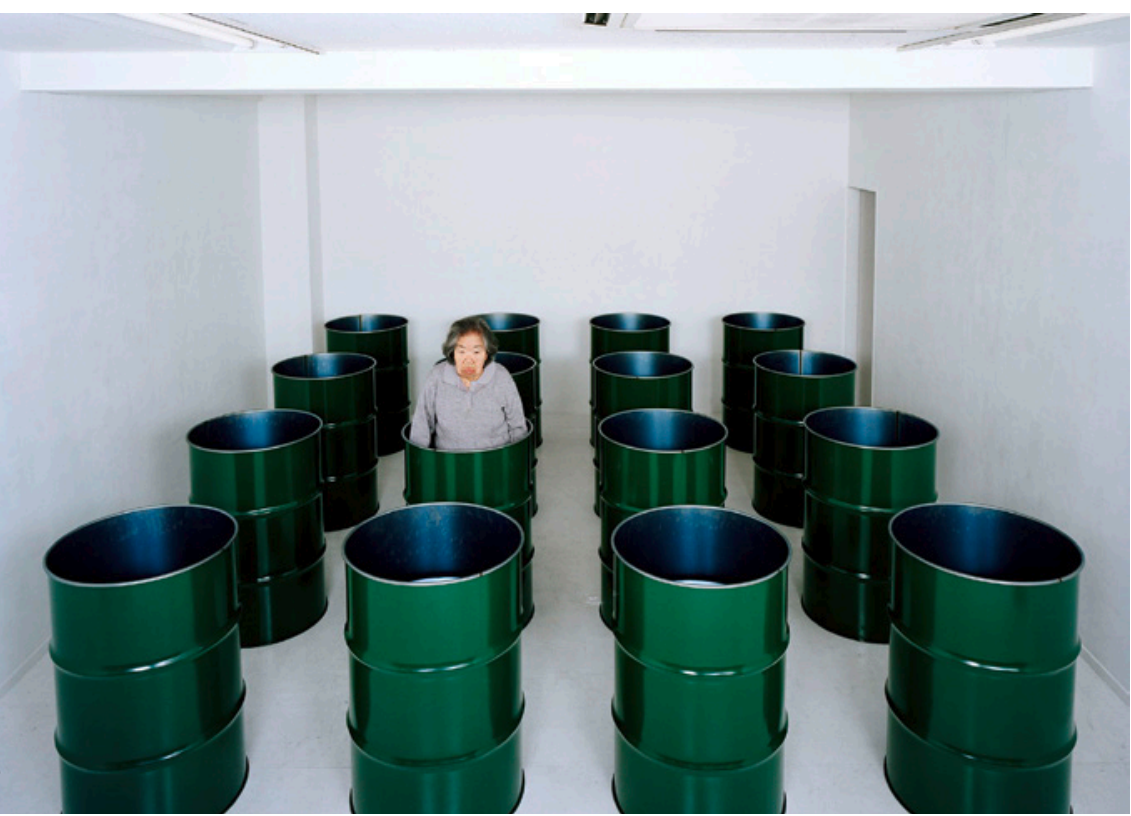

Imagen 5. Tatsumi Orimoto, 16 drums and 16 people, 2001-2002.

Hay que tener en cuenta, además, que para trabajar con imágenes es necesaria una alfabetización visual y un conocimiento de cómo se construyen los mundos simbólicos, y esto requiere un proceso de formación previo. El conocimiento del medio fotográfico permite aplicar las herramientas que los lenguajes artísticos proveen como instrumento de amplificación de los campos y las metodologías de trabajo que se pueden activar en un aula. Esto enriquece de forma considerable todo el proceso de aprendizaje en cualquier nivel educativo.

El uso de las imágenes como herramienta docente y de investigación será lógicamente diferente de su presencia social, entendiendo esta última como la práctica cotidiana no reflexionada que desarrollan los seres humanos en su ámbito y entorno social y cultural. El uso de las imágenes en la formación del profesorado debe generar, por el contrario, procesos de reflexión crítica, de activación del pensamiento y de construcción de pensamiento a partir de las imágenes fotográficas. Las imágenes, por tanto, como instrumento de formación, se deben entender siempre como un instrumento de conocimiento, de creación meditada y de narración constructiva.
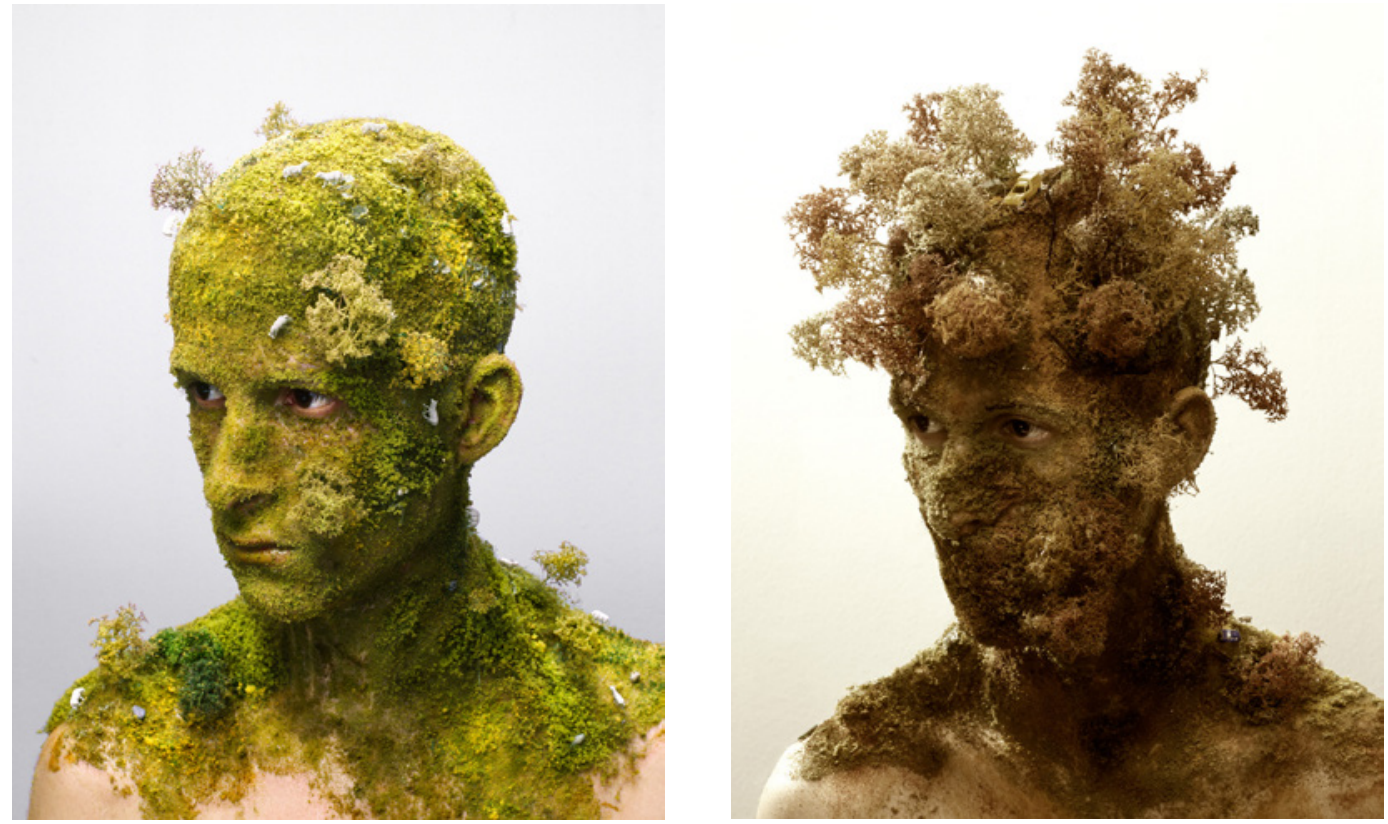

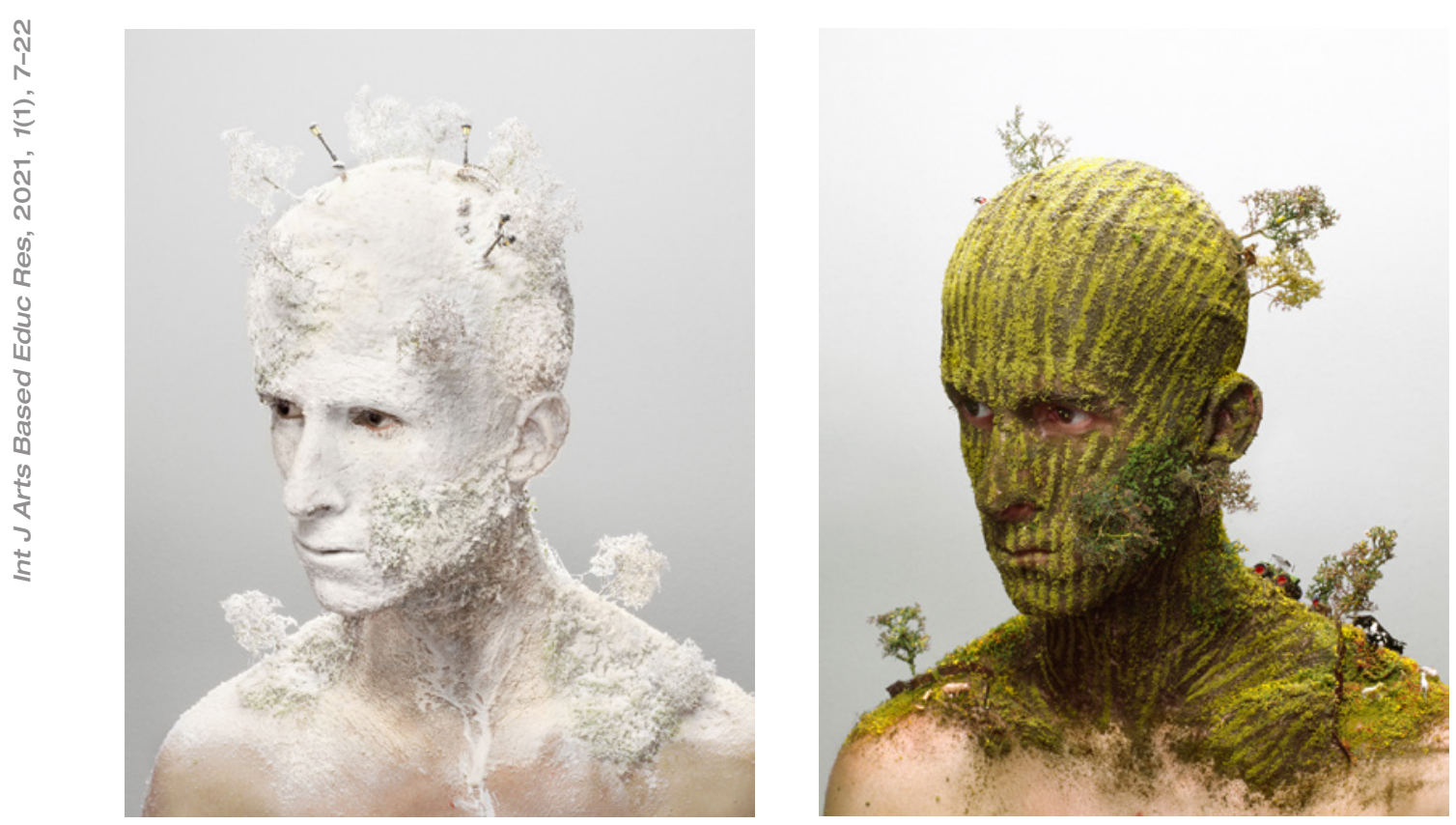

Imágenes 6, 7, 8, 9 y 10. Landscape I. Self Portraits, Levi van Veluw (https://levivanveluw.com/work/older-works-portraits-part-i).

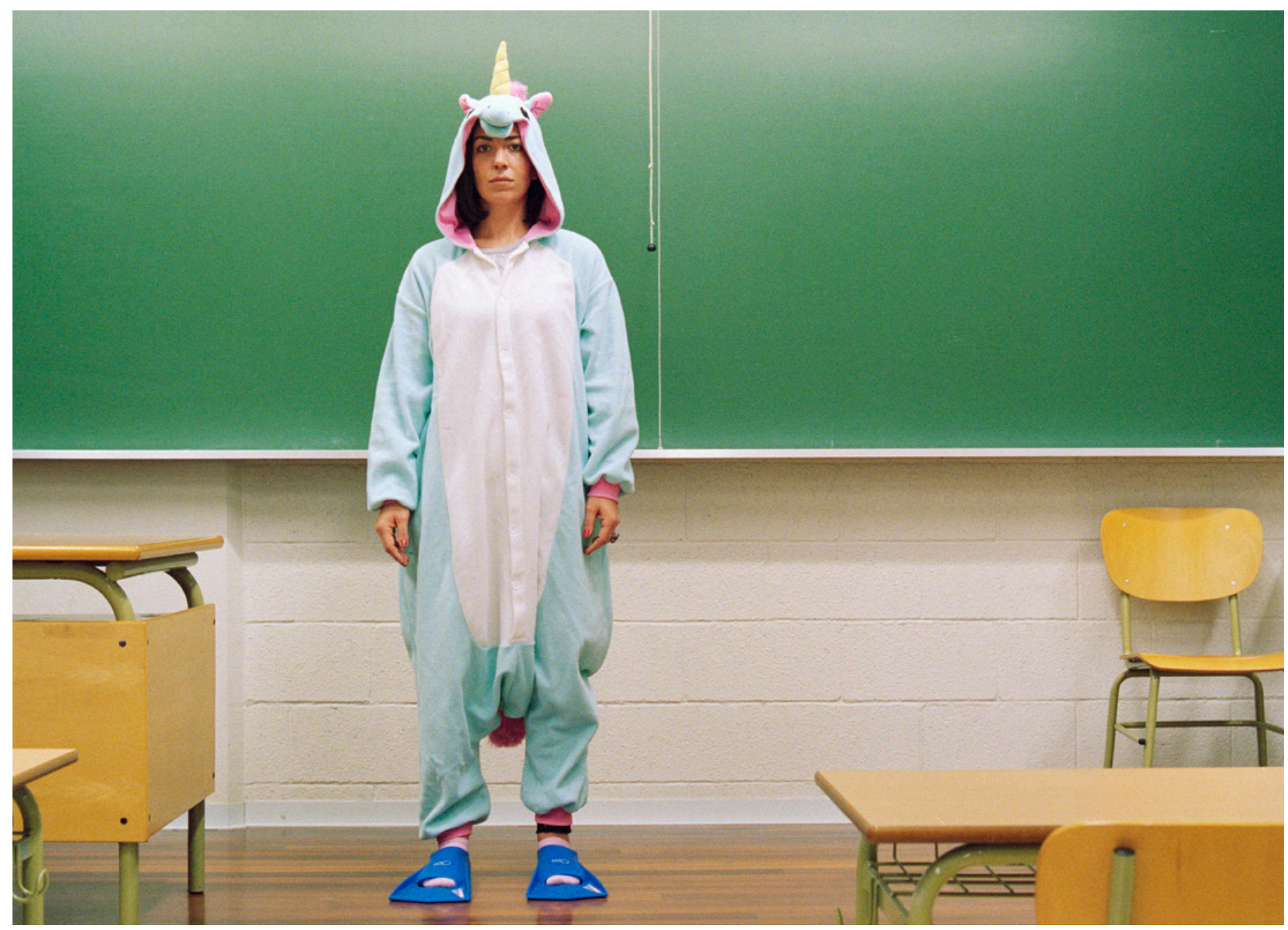

Imagen 11. Alumna realizando representando su acción artística para el proyecto. Fuente: autores. 
El hecho de que las imágenes son una forma de pensamiento y de construcción de conocimiento en sí mismas, tan válidas como cualquier forma de narración textual que se utilice para ello, es un concepto que todavía está lejos de ser asumido por una parte importante de los docentes en todos los niveles educativos. Esto es una de las causas que hace más urgente el trabajo con la fotografía, dado que es una de las principales y más accesibles herramientas de generación de imágenes, vinculada con los entornos y prácticas sociales contemporáneas.

Además, debemos contribuir a la comprensión de la fotografía como medio de creación artística, y entender el poder simbólico, el potencial creativo y la capacidad para construir narrativas de extrañamiento de la realidad y el entorno cotidiano. Estamos ante un medio que nos permite cuestionar nuestra posición en el mundo de forma permanente, como hace el arte.

Desde el punto de vista de la fotografía como creación artística en educación nos referiremos a la fotografía narrativa contemporánea (Mesías-Lema, 2012, p. 143). Las producciones fotográficas propias del arte contemporáneo se centran en relatos de hechos ficticios, en la capacidad o habilidad para narrar a través de la semiótica visual y en el discurso, es decir, en su capacidad retórica dentro del contexto cultural en que se produce. Por tanto, entendemos que la fotografía narrativa contemporánea es aquella que problematiza sus funciones comunicativas dentro del campo de las artes visuales y se implica en la construcción de sus propios discursos bajo un activismo basado en la resistencia comunicativa y política. Es la fotografía que se cuestiona a sí misma.
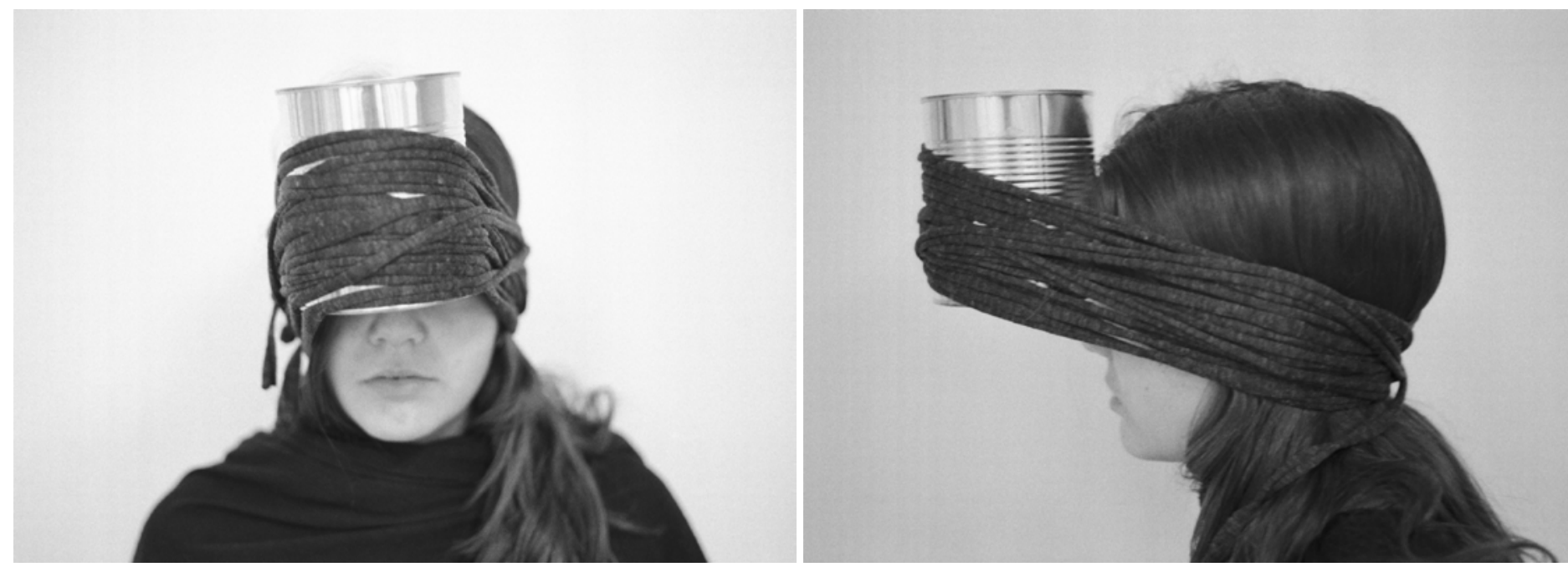

Imágenes 12 y 13. Maneras de Hacer Mundos. Fotografía analógica. València, 2016. Fuente: Autores.

El proyecto "Maneras de hacer mundos" (https://culturavisual.cc/waysofworldmaking/) se desarrolla dentro de estos procesos de investigación, reflexión y práctica educativa que deben estar integrados en la experiencia desarrollada en las aulas, que tienen como base la fotografía en el trabajo de investigación artístico-educativa. El objetivo de esta ABER es generar pensamiento visual, construyendo un discurso fotográfico, desde la práctica y la acción artística, estética y performativa.

El proyecto escoge su nombre basándose en la idea principal que subyace en los textos del filósofo Nelson Goodman (1995) sobre la construcción de nuevos mundos como forma de aprendizaje y de construcción de conocimiento. Se parte de una experiencia artística performativa que tiene en el concepto de extrañamiento una forma de encontrar nuevos posicionamientos personales respecto al aula, a la docencia y al papel del docente y del propio alumnado y sus prácticas como agentes de transformación. Entendemos que el proceso educativo es esencialmente un proceso de creación de nuevos mundos, con el recurso de la imaginación creativa como forma de generar pensamiento 
activo y construir conocimiento, porque "los mundos no sólo se hacen por medio de lo que se dice literalmente sino también por medio de lo que se dice metafóricamente" (Goodman, 1990, p. 38).

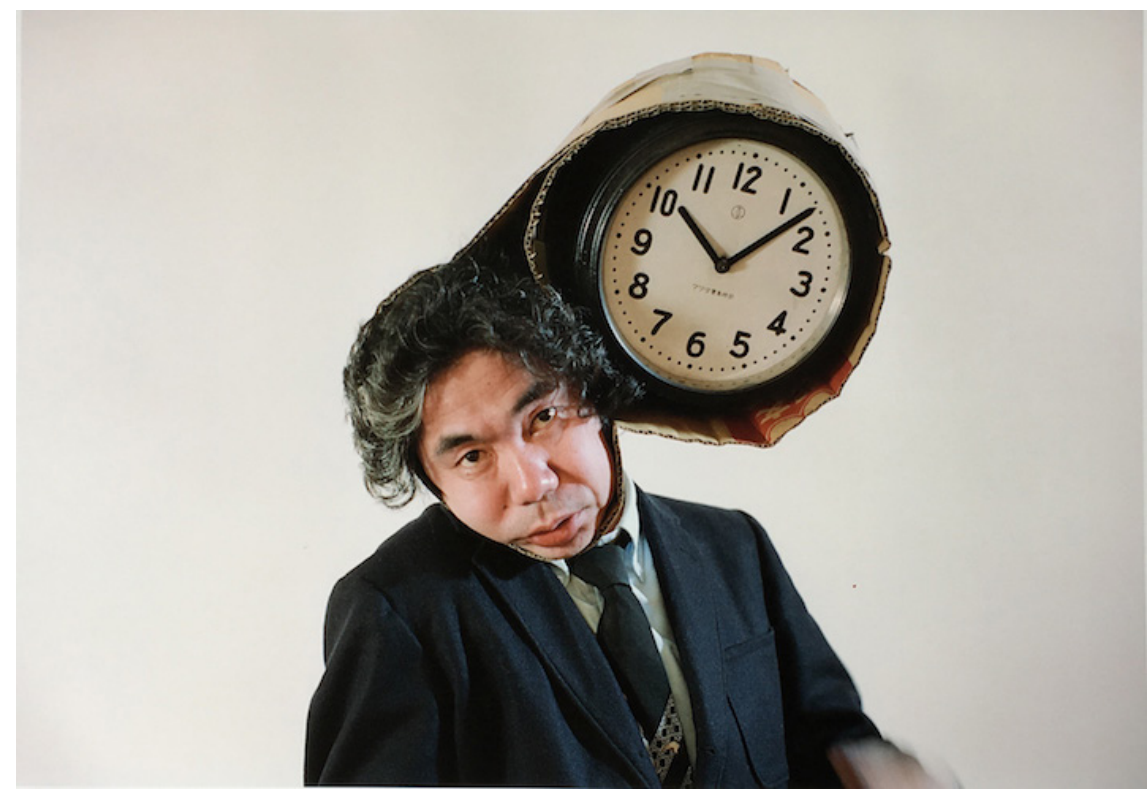

Imagen 14. Tatsumi Orimoto, Clock Man, 1991

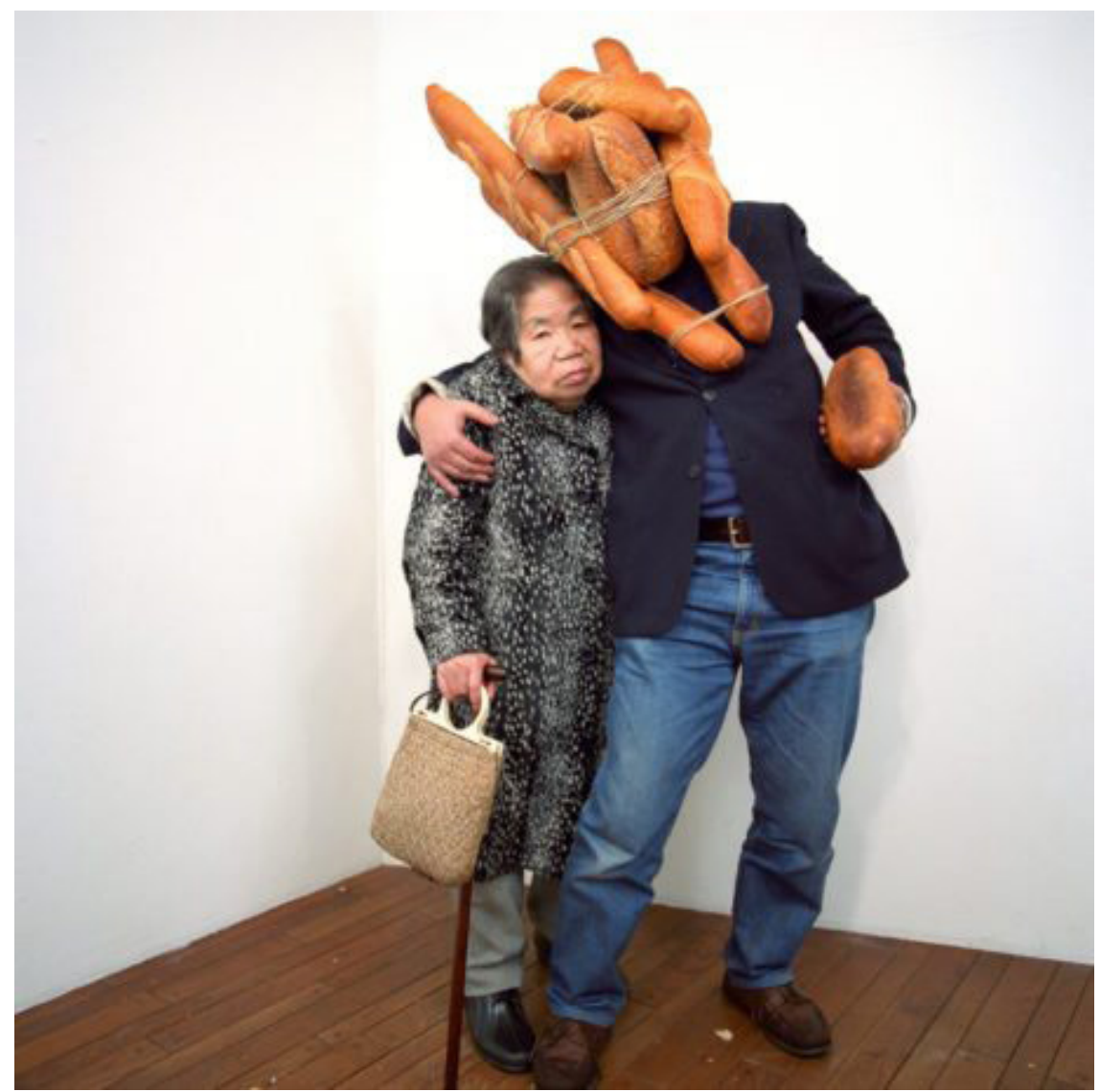

Imagen 15. Tatsumi Orimoto, Bread Man Son Alzeimer Mama, 1996.

"Maneras de hacer mundos" es un ABER que trata de construir modelos y experiencias indagadoras para subvertir el aula con la fotografía como método científico (Ramon, 2019a, 2019b; Mesías-Lema, 2017), a partir de estrategias de extrañamiento, que desafíen la propia predisposición del alumno a ver el aula de una forma determinada y, 
consecuentemente, a conceptualizar la educación de una manera muy reduccionista. Esto permite generar un cambio en el pensamiento del futuro docente y un replanteamiento personal de lo que es el proceso educativo a nivel metodológico. Con ello se genera una reflexión en la que se demuestra que la fotografía tiene un enorme poder de transformación como herramienta de aprendizaje en el proceso indagador, desde una posición estética.

Así mismo, se conecta con un modo de desarrollo científico basado en el self-study, una forma de investigar que parte de la autorreflexión como formación docente. Posibilita una comprensión más profunda acerca de la relación entre enseñanza y aprendizaje (Loughran \& Rusell, 2002). En la investigación basada en el self-study es fundamental la colaboración y el trabajo conjunto con otros docentes, como parte del proceso de investigación (Silva-Peña et al, 2017).

En esta ABER, los estudiantes construyen una propuesta fotográfica, a partir de las acciones e interacciones de su propio cuerpo como elemento referencial participante y activo, en una acción performativa pensada para ser documentada visualmente. En este proceso, deben activar su pensamiento imaginativo y creativo para formular una fotografía que deben construir y visualizar previamente. Eso los lleva a ejercer una mirada completamente nueva y diferente, hacia un entorno que perciben como espacio formalizado de educación y que ahora deben ver con otros ojos, a partir de ese proceso de extrañamiento. Han de interpretar, a partir de su propia presencia, la de su cuerpo, y de la presencia y el cuerpo de los demás y de los objetos que, por azar o de forma meditada, han decidido utilizar en su composición visual. El extrañamiento funciona así como objetivo transformador de aprendizaje.

Una de las consecuencias más importantes de este tipo de prácticas investigadoras es constatar la necesaria implicación del profesorado en las prácticas docentes. Implicándose como artista-docente-investigador, el profesor logra que se genere un proceso de interacción, compromiso compartido y cooperación profesor-alumno. El compromiso de los docentes con todo el proceso, como parte activa y con la fotografía, cambia por completo el clima y los condicionantes del entorno, construyendo en la experiencia generada un proceso de aprendizaje y de diálogo entre profesores y alumnos sobre las prácticas que están llevando a cabo de forma conjunta. El diálogo se extiende, en esa misma experiencia, a los docentes implicados en un trabajo que es necesariamente colectivo.

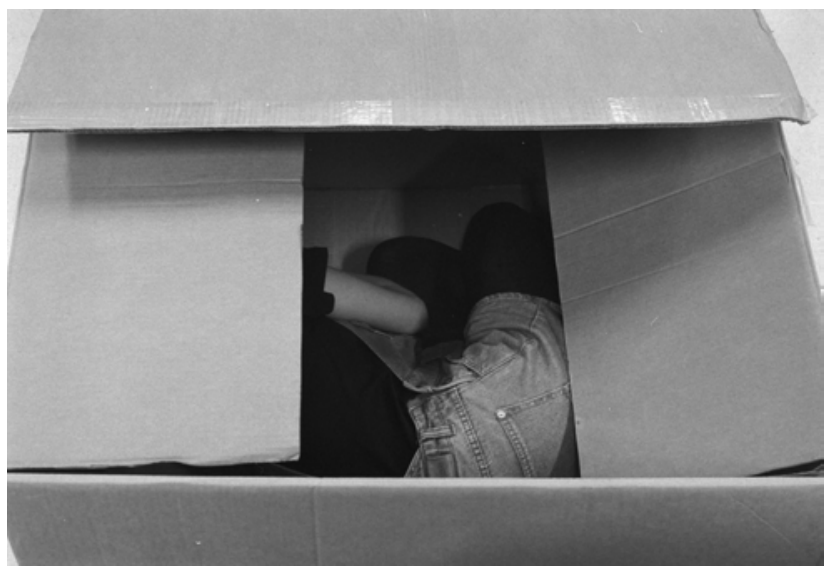

Imagen 16. Una alumna encerrada en una caja de cartón durante su acción artística en el desarrollo del proyecto. Fuente: autores.

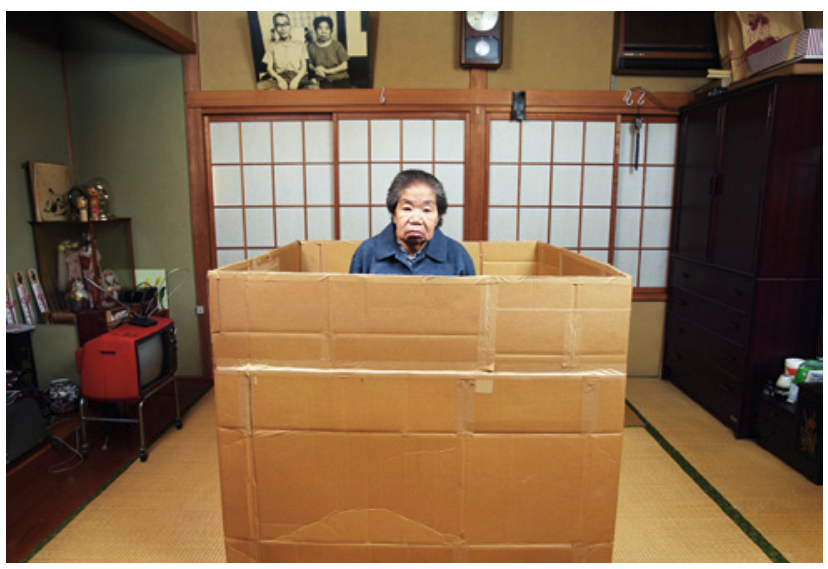

Imagen 17. Tatsumi Orimoto, Art Mama, in the big box, 1997 
Todo ello dentro del marco de reflexión pedagógica que implica la comprensión, para todos los agentes implicados, de que existen formas de trabajo docente, de aprendizaje a partir de la construcción de mundos creativos (Goodman, 1990, 1995) y coparticipados, más allá de las zonas de confort educativas que la institucionalización tiende a crear. Estos modelos de investigación rompen, a partir del proceso de extrañamiento generado, con la concepción estática y bidireccional del aprendizaje y alientan hacia el uso y la reinterpretación educativa de materiales, entornos, objetos y espacios cotidianos. Ello permite a los futuros docentes observarse en relación con estos conceptos y a su futura práctica como profesionales, bajo una perspectiva diferente, estimulando a abrir campos de acción pedagógica que tengan la fotografía como instrumento de creación simbólica y creación de nuevos conocimientos no convencionales y, por ello, mucho más enriquecedores y significativos.

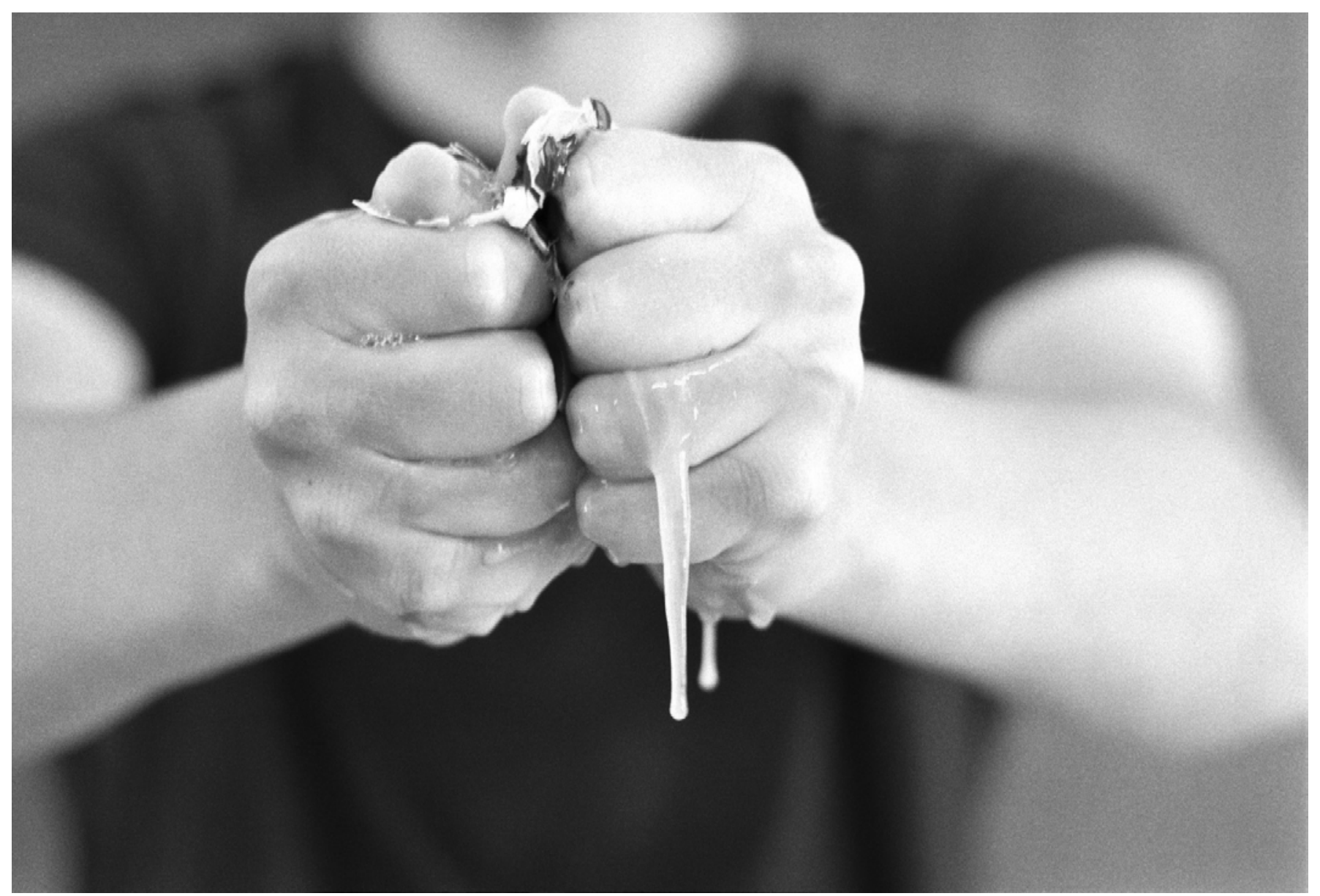

Imagen 18. Maneras de Hacer Mundos. Fotografía analógica. València, 2016. Fuente: Ricard Ramón. 


\section{REFERENCIAS BIBLIOGRÁFICAS}

Agra Pardiñas, M. J. (2005). "El vuelo de la mariposa: la investigación artístico-narrativa como herramienta de formación". En Marín, R. (coord.). Investigación en Educación Artística. Publicaciones de la Universidad de Granada, 127-150.

Barone, T. y Eisner, E. (2006). "Arts-Based Educational Research". En Green y Elmore (eds.). Complementary Methods for Research in Education. American Educational Research Association, 95-109.

Barone, T. y Eisner, E. (2012). Arts Based Research. Sage Publications.

Bauman, Z. (2003). Modernidad líquida. Fondo de Cultura Económica.

Bolívar, A., Domingo, J. y Fernández, M. (2001). La investigación biográfico-narrativa en educación. Enfoque y metodología. La Muralla.

Bresler, L. (ed.) (2007). International Handbook of Research in Arts Education. Springer.

Butler-Kisber, L. (2010). Qualitative Inquiry: Thematic, Narrative and Arts-based Approaches. Sage Publications.

Cahnmann-Taylor, M. y Siegesmund, R. (2008). Arts-based Research in Education: Foundations for Practice. Routledge.

Denzin, N. (1989). Interpretative biography. Qualitative Research Methods. Sage Publications.

Denzin, N. K. y Lincoln, Y. S. (2011). The sage handbook of qualitative research. Sage Publications.

Eisner, E. (1998). El ojo ilustrado. Indagación cualitativa y mejora de la práctica educativa. Paidós.

Eisner, E. y Day, M. D. (2004). Handbook of Research and Policy in Art Education. NAEA.

Goodley, D. et al. (2004). Researching life stories. Method, theory and analysis in a biographical age. Routledge.

Goodman, N. (1990). Maneras de hacer mundos. Visor.

Goodman, N. (1995). De la mente y otras materias. Visor.

Hernández, F. (2008). La investigación basada en las artes: Propuestas para repensar la investigación en Educación. Educatio Siglo XXI, 26, 85-118.

James, E. A.; Milenkiewicz, M.T. y Bucknam, A. (2008). Participatory Action Research for Educational Leadership. Sage Publications.

Janesick, V. J. (2003). The Choreography of Qualitative Research Design: Minuets, Improvisations and Crystallization. En Lincoln, N. K. y Denzin, Y. S. (eds). Strategies of Qualitative Research. Sage Publications, 379-400.

Leavy, P. (2015): Methods meets Art: Arts-based Research Practice. Guilford Press.

Leavy, P. (ed.) (2018). Handbook of Arts-Based Research. Guilford Press.

Loughran, J. y Russell, T. (2002). Improving Teacher Education Practices Through SelfStudy. Routledge.

Marín-Viadel, R. (coord.). (2005). Investigación en Educación Artística. Universidad de Granada. 
Marín-Viadel, R. (2011). La Investigación en Educación Artística. Educatio Siglo XXI, 29 (1), 211-230. https://revistas.um.es/educatio/article/view/119951

Marín-Viadel, R. (2019). Microteorías inestables sobre artes visuales y educación. En Miradas Caleidoscópicas. Educación Artística visual en las culturas contemporáneas. Universidad Pedagógica Nacional.

Mesías-Lema, J. M. (2012). Fotografia y Educación de las Artes Visuales: el fotoactivismo educativo como estrategia docente en la formación del profesorado. Universidad de Granada,

Mesías-Lema, J. M. (2017). Art Teacher Training: a photo essay. International Journal of Education through Art, 13(3), 395-404. http://dx.doi.org/10.7203/eari.9.10927

McNiff, S. (2004). Art-based Research. Jessica Kingsley.

Mulvihill, T. \& Swaminathan, R. (2020): Arts-Based Educational Research and Qualitative Inquiry: Walking the Path. Routledge.

Prosser, J. (ed.). (1998). Image-based Research. A sourcerbook for qualitative researchers. Falmer Press.

Ramon, R. (2019a). Prácticas artísticas de visualización entre cuerpo y objeto en entornos de mediación pedagógica. Arte, Individuo y Sociedad, 31(13), 509-526. https://doi. org/10.5209/aris.60881

Ramon, R. (2019b). La fotografía como forma de conocimiento pedagógico, frente a los otros y el mundo. Invisibilidades. Revista ibero-americana de pesquisa em educação, cultura e artes, 11, 20-27.

Sandlin, J., Schultz, Brian D. y Burdick, J. (eds). (2010). Handbook of Public Pedagogy. Education and learning beyond schooling. : Routledge.

Sefton-Green, J., Thomson, P., Jones, K., y Bresler, L. (2011). The Routledge International Handbook of creative learning. Routledge.

Silva-Peña, I., Moreno Tello, P., Santibáñez Gómez, D., Gutiérrez Villegas, M., Flores González, M., Orrego Lepe, C., y Nocetti de la Barra, A. (2017). Self-study como proceso de formación de formadores/as: reflexiones en medio del camino. En G. González-García, I. Silva-Peña, C. Sepúlveda-Parra, \& T. Del Valle Contreras (Eds.), Investigación para la formación de profesores. Santiago de Chile: Universidad Católica Silva Henríquez.

Springgay, S., Irwin, R. L. \&Wilson Kind, S. (2005). A/r/tography as Living Inquiry Through Art and Text. Qualitativelnquiry, 11(6), 897-912.https://doi.org/10.1177/1077800405280696

Sullivan, G. (2005). Art practice as research: Inquiry in the Visual Arts. Oaks: Sage. 
José María Mesías Lema es profesor de Educación Artística en la Universidad de A Coruña. Ha sido Vicedecano de Relaciones Internacionales y Adjunto al Vicerretorado como Director del centro de intervención artística NORMAL (www.istoenormal.org). Es el director del grupo de investigación internacional ArteFacto-UDC (www.arte-facto. org), centrado en los procesos artísticos contemporáneos en contextos de diversidad. Activista y defensor de los derechos humanos centra su investigación en como la educación artística es sensible a la vida de los estudiantes. Su última investigación se centra en el trabajo con artistas contemporáneos que habitan los centros educativos para generar laboratorios de aprendizaje en Educación Artística.

jose.mesias@udc.es

Ricard Ramon. Doctor en Estética y Teoría de las Artes. Licenciado en Historia del Arte y en Bellas Artes. Profesor de educación artística en el Departamento de Didáctica de la Expresión Musical, Plástica y Corporal, investigador del Instituto de Creatividad e Innovaciones Educativas, miembro del grupo de investigación CREARI, coordinador de la Unidad Mixta de Investigación EFÍMERE y miembro del grupo Arte-Facto.

ricard.ramon@valencia.edu 